\title{
Algumas considerações sobre o crer e o saber
}

\author{
Dilson Ferreira da CRUZ \\ (Universidade de São Paulo)
}

RESUMO: Embora sejam pertencentes a um mesmo universo cognitivo - segundo as palavras de Greimas em Du sens II -, o crer e o saber podem se encontrar em relação de oposição e, desse modo, constituir uma paixão ainda pouco estudada: a ingenuidade. Este artigo procura examiná-la da perspectiva da semiótica tensiva e mediante o confronto com outras paixões.

PALAVRAS-CHAVE: crer e saber; ingenuidade; fanatismo; paixão; modalidades

RÉSUMÉ: Selon Greimas, le croire et le savoir appartiennent à un même univers cognitif. Cependant ces deux modalités peuvent se trouver dans une situation d'opposition et constituer une passion peu étudiée: la naïveté. Cet article cherche à l'examiner selon le regard de la sémiotique tensive et moyennant la confrontation avec d'autres passions.

MOTS-CLÉS: croire et savoir; naïveté; fanatisme; modalités 
A o menos na literatura, a ingenuidade tem dado à luz filhos ilustres: D. Quixote, Candide, M. Jourdan, Charles Bovary, o Príncipe Michkin, de O idiota, Meursault, Poliquarpo Quaresma, Rubião e, por que não? Brás Cubas. Sim, é verdade, são sujeitos muito diferentes, mas que têm em comum o fato de serem, em graus e modos variados, ingênuos... Contudo, se achar um ingênuo não é tarefa difícil, defini-lo não é assim tão simples, pois, nesse caso, nossos dicionários, porto seguro de semioticistas à deriva, não se mostram muito acolhedores e adotam o estilo dos telégrafos. O Houaiss, por exemplo, contenta-se com sinônimos e afirma que ingenuidade é "qualidade, caráter de ingênuo; simplicidade, candura, singeleza" e que ingênuo seria aquele que "denota ou trai inocência, candura, sinceridade, simplicidade". O Aurélio não é mais loquaz; conta que ingênuo é aquele no qual "não há malícia”; que é "simples, franco...". A parcimônia de nossos conterrâneos nos levou a buscar socorro em outras paragens.

É assim que acabamos por aportar no francês Le Petit Robert, que afirma que naïveté (ingenuidade) é:

Excesso de confiança, de credulidade, freqüentemente resultante de ignorância, de inexperiência ou de falta de reflexão, marca desse estado de espírito.

E também no International Dictionary of English, da Universidade de Cambrigde, que informa que naivety (ingenuidade) é:

Confiança reprovável baseada em falta de experiência.

E que naive (ingênuo) é:

Aquele que apresenta uma propensão reprovável a acreditar que alguém está dizendo a verdade, que as intenções das pessoas são em geral boas ou que a vida é simples.

Nas duas definições, o ingênuo não é apenas aquele que está em disjunção com um saber, mas que apresenta um crer excessivo e, por essa razão, reprovável. A ingenuidade nasce, portanto, de uma combinação especial das modalidades do crer e do saber: a primeira, demasiada; a segunda, escassa. Assim, a evolução de ambas seria inversamente proporcional: quanto menor o saber, maior o crer. Observe-se que a natureza do saber em questão não é indiferente, pois o parvo, o inábil e mesmo o incompetente também estão em disjunção com um saber, mas este não implica, necessariamente, um crer excessivo. Segundo Houaiss, parvo é aquele que é pouco inteligente, e inábil, aquele "que não está apto a executar ato ou realizar negócio com validade jurídica. Incapaz”. Ora, no primeiro caso, o não-saber está diretamente relacionado a um não-poder e, no segundo, não implica qualquer relação com o crer. 
Inicialmente, observe-se que, conforme sugere o dicionário inglês, o ingênuo ignora que seu interlocutor mente ou que suas intenções não são aquelas que aparentam ser. Em seguida, veja-se que a propensão do ingênuo para a crença indica que esse sujeito possui um campo de presença amplo, que lhe possibilita relacionar-se com uma extensa gama de objetos de saber. Embora não se possa afirmar de forma peremptória, é provável que a relação do ingênuo com sua crença tenda a ser átona, pois uma ligação tônica talvez dificultasse sua adesão a outras crenças. A comparação com algumas disposições de espírito, relativas ao crer, ser-nos-á útil. Veja-se, por exemplo, o fanatismo, definido pelo Houaiss como:

faccionismo partidário; adesão cega a um sistema ou doutrina; dedicação excessiva a alguém ou algo; paixão.

\section{E pelo Petit Robert como:}

Fé exclusiva em uma doutrina, uma religião, uma causa, acompanhada de um zelo absoluto em sua defesa, o qual, frequentemente, conduz à intolerância e à violência.

No fanatismo há, também, um crer desmesurado, porém, nesse caso, o sujeito não apresenta uma propensão a entrar em conjunção com vários objetos de saber. $\mathrm{O}$ fanático é justamente aquele que tem uma fé exclusiva e que em função dessa fé única não pode crer em nada mais, especialmente se isso confrontar suas crenças... O fanático, diferentemente do ingênuo, é detentor de um querer também intenso e excessivo, o qual é responsável por sua paixão, pelo seu zelo, por seu apego às convicções. A convergência e a intensidade das modalidades do crer e do querer são responsáveis pela tonicidade que caracteriza as relações do fanático com seu objeto. Seu querer funciona, portanto, como um catalisador de suas convicções, o que, de certa forma, torna sua relação com o objeto hipertensa e explicaria sua violência e seu zelo excessivo.

Por outro lado, o saber átono do ingênuo funcionaria como um inibidor da tensão de sua relação com o objeto e tornaria suas crenças voláteis, efêmeras: da mesma maneira que as adquiriu, pode perdê-las. Por isso, o ritmo ou andamento de sua relação com os objetos é mais veloz. O saber átono explica ainda por que o investimento semântico dos objetos mostra-se secundário para o ingênuo que, ao contrário do fanático, tem um crer extenso, mas átono.

Enfim, embora tanto o crer do fanático quanto o do ingênuo sejam excessivos, o excesso se deve, no primeiro caso, à intensidade e, no segundo, à extensidade. $\mathrm{O}$ fanático tem um crer intenso que reduz seu campo de presença, o torna pouco extenso e faz com que raros sejam os objetos de saber visados e poucos aqueles nos quais ele crê. Por outro lado, o crer do ingênuo é extenso, por isso ele tende a capturar ou apreender tudo o que lhe dizem, passando a ter como suas crenças que até então não o eram. Em contrapartida, sua ligação é átona, pouco intensa. O crer intenso do fanático o leva a executar operações de triagem, que o fazem dedicar-se a poucas crenças, ao passo que o crer extenso do ingênuo o induz a realizar operações de mistura, em que predominam valores de universo, pois, conforme foi dito, ele tende a crer em tudo que lhe dizem. $\mathrm{O}$ quadro a seguir resume as características de um e de outro. 
Intensidade e extensidade das modalidades na ingenuidade e no fanatismo

\begin{tabular}{|l|c|c|c|c|}
\hline \multirow{2}{*}{ Modalidades } & \multicolumn{2}{|c|}{ Ingenuidade } & \multicolumn{2}{c|}{ Fanatismo } \\
\cline { 2 - 5 } & Extensidade & Intensidade & Extensidade & Intensidade \\
\hline Crer & Ampla & baixa & reduzida & alta \\
\hline Saber & Reduzido & baixa (?) & reduzida & nula \\
\hline Querer & ??? & ??? & reduzida & alta \\
\hline Operações & \multicolumn{2}{|c|}{ mistura } & \multicolumn{2}{c|}{ triagem } \\
\hline
\end{tabular}

Embora a ingenuidade caracterize-se pela oposição entre o crer e o saber; nem sempre essa relação se estabelece entre as duas modalidades. Por exemplo, a definição de fé proposta por Houaiss não as contrapõe, mas apenas supõe a disjunção do sujeito que crê com o saber. Veja-se a definição do dicionário:

crença religiosa sem fundamento em argumentos racionais, embora eventualmente alcançando verdades compatíveis com aquelas obtidas por meio da razão.

Ao contrário do ingênuo, o sujeito que tem fé não é aquele que crê porque ignora algo, mas simplesmente o que crê apesar de ignorar fatos que poderiam (ou não) corroborar sua crença. Desse modo, não haveria cabimento alguém afirmar que tem fé que a água ferverá a $100^{\circ} \mathrm{C}$ no nível do mar, pois, nesse caso, o crer está alicerçado em um saber que não se opõe a tal convicção. Por outro lado, a afirmação de que existe vida fora da Terra não pode ser considerada nem uma verdade cabal nem uma ingenuidade, pois não há elementos que corroborem ou neguem tal hipótese. Entra-se, portanto, no campo da fé. Finalmente, a crença de que Marte é habitado por homenzinhos verdes soaria ingênua, visto que há informações, ou um saber suficiente, que comprovam a impossibilidade de tal fato; logo, o saber disponível não autorizaria tal crença. Concluise, portanto, que a confiança do ingênuo é excessiva não exatamente porque desconheça algo, mas porque não sabe algo que deveria ser cabalmente conhecido por ele - ao menos no entendimento de um terceiro sujeito observador, que julga que ele não teve a competência necessária para realizar seu fazer interpretativo - e não a teve por não dispor de determinado saber. Um exemplo extraído de um dos famosos diálogos de Brás Cubas com Marcela talvez ajude a deixar tudo mais claro:

Ela ouvia-me e ria, com - expressão cândida, - cândida e outra coisa, que eu nesse tempo não entendia bem, mas agora, relembrando o caso, penso que era um riso misto, como devia ter a criatura que nascesse, por exemplo, de uma bruxa de Shakespeare com um serafim de Klopstock. [...]. Assim foi que um dia, como eu lhe não pudesse dar certo colar, que ela vira num joalheiro, retorquiu-me que era um simples gracejo, que o nosso amor não precisava de tão vulgar estímulo. 
— Não lhe perdôo, se você fizer de mim essa triste idéia, concluiu ameaçando-me com o dedo.

[...] Depois [...] continuou a falar daquilo com simplicidade e franqueza. Jamais consentiria que lhe comprassem os afetos. Vendera muita vez as aparências, mas a realidade, guardava-a para poucos. Duarte, por exemplo, o alferes Duarte, que ela amara deveras, dois anos antes, só a custo conseguia dar-lhe alguma coisa de valor, como me acontecia a mim; ela só lhe aceitava sem relutância os mimos de escasso preço, como a cruz de ouro, que lhe deu, uma vez, de festas.

— Esta cruz...

$[\ldots]$

- Mas essa cruz, observei eu, não me disseste que era teu pai que...

Marcela abanou a cabeça com um ar de lástima:

- Não percebeste que era mentira, que eu dizia isso para te não molestar?

Vem cá, chiquito, não sejas assim desconfiado comigo... Amei a outro; que importa, se acabou? Um dia, quando nos separarmos...

— Não digas isso! bradei eu.

— Tudo cessa! Um dia...

Não pôde acabar; um soluço estrangulou-lhe a voz; estendeu as mãos, tomou das minhas, conchegou-me ao seio, e sussurrou-me baixo ao ouvido:

- Nunca, nunca, meu amor! Eu agradeci-lho com os olhos úmidos. No dia seguinte levei-lhe o colar que havia recusado.

- Para te lembrares de mim, quando nos separarmos, disse eu.

Marcela teve primeiro um silêncio indignado, depois fez um gesto magnífico: tentou atirar o colar à rua. Eu retive-lhe o braço; pedi-lhe muito que não me fizesse tal desfeita, que ficasse com a jóia. Sorriu e ficou.

(Assis, vol. I, 1997:535-536)

Marcela não apenas afirma explicitamente que não quer o colar, que o amor de ambos "não precisava de tão vulgar estímulo" e que ela não "consentia que lhe comprassem os afetos", mas também simula uma série de comportamentos os quais se veria constrangida a adotar em virtude dos sentimentos que teria: usar de "gracejos", falar "com franqueza e simplicidade, sussurrar", ter "soluços, voz estrangulada, um olhar indignado...”. Além disso, simula tentar atirar longe o colar como se tal ato fosse uma reação quase instantânea, provocada pelas palavras de Brás Cubas. Como se sabe, ela mentia: seu amor não era desinteressado, mas de um caráter bem utilitário; em momento algum pensou em desfazer-se da jóia que tanto cobiçara. Ao contrário: manipulara Brás Cubas - valendo-se inclusive da intimidação com a ameaça da separação - para que ele lhe comprasse a peça, o que ele faz, sem dar-se conta, naquele momento, de que era vítima de uma das manipulações mais banais.

Contudo, afirmar que Brás Cubas acreditou em Marcela por não saber que ela mentia não resolve o problema; equivale a dizer que acreditou, porque não duvidou. $\mathrm{O}$ não saber que está na base de sua ingenuidade não se refere ao fato de ele ignorar a mentira da amada, mas à sua incompetência para realizar um fazer interpretativo correto. Ora, não se pode qualificar de ingênuo aquele que se deixa levar por argumentos que pareciam sólidos e verdadeiros sob vários pontos de vista, mas que, ao final, mostraram-se falaciosos. Nesse caso, o convencimento seria devido à habilidade do fazer do sujeito da persuasão, e não à bisonhice daquele que exerce o fazer interpretativo. A ingenuidade de Brás Cubas reside no fato de ele não atinar com o ardil 
de Marcela; não perceber que sua recusa não passava de uma estratégia - bem chinfrim, diga-se de passagem - para convencê-lo a dar-lhe o colar. Sabe-se que a moça criou dois programas de persuasão, cada qual executado por um actante, embora ambos estejam sincretizados em um mesmo ator: ela própria. O primeiro programa opera na dêixis da persuasão (comprar o colar), o segundo, concebido para fracassar, opera na dêixis da dissuasão (não comprar o colar). Tal estratégia poderia se enquadrar no que Greimas chama de "persuasão antifrástica: o enunciado persuasivo é mostrado como uma persuasão a recusar com a intenção oculta de que seja lido, no fazer interpretativo do sujeito manipulado, como uma dissuasão a recusar” (Greimas, 1983:215). Pede-se o que não se quer para se obter o que é desejado. O que Brás Cubas ignora é precisamente a persuasão antifrástica, isto é, o fato de o programa "não comprar colar" ter sido concebido para fracassar. O êxito de Marcela, no entanto, deve-se menos à sua habilidade e mais à incompetência do fazer interpretativo de Brás Cubas.

Voltando às definições dos dicionários, agora de posse das conclusões sobre a estratégia de Marcela, conclui-se que o que torna o sujeito ingênuo não é tanto sua disjunção com a natureza epistemológica de um fato (ser ou não ser), mas com uma competência para interpretar o contrato veridictório que lhe é proposto. Havia indícios suficientes de que Marcela mentia, como a expressão que era "cândida e outra coisa”, e que Brás percebeu, mas não soube interpretar na ocasião, mas posteriormente reconheceu ser semelhante a "um riso misto, como devia ter a criatura que nascesse, de uma bruxa de Shakespeare com um serafim de Klopstock”. Além disso, o comportamento dela, negando o interesse e a necessidade do presente ao mesmo tempo em que aludia ao mimo que havia recebido de outro amante já deviam indicar a Brás Cubas que sua amada, afinal, mentia. Finalmente, observe-se que ele próprio, agora na posição de observador, reconhece sua inépcia ao recordar o episódio alguns anos mais tarde, quando reencontra a antiga namorada:

[...] perguntei a mim mesmo por que motivo fizera tanto desatino. Não era esta certamente a Marcela de 1822; mas a beleza de outro tempo valia uma terça parte dos meus sacrifícios? [...] O rosto dizia-me que não; ao mesmo tempo, os olhos me contavam que, já outrora, como hoje, ardia neles a flama da cobiça. Os meus é que não souberam ver-lha; eram olhos da primeira edição.

Na indagação de Brás Cubas sobre os próprios desatinos está implícito o reconhecimento de que seu crer fora excessivo, de que na ocasião ele devia saber algo que agora sabe. Reconhece, enfim, que nos olhos de "Marcela já outrora, como hoje, ardia neles a flama da cobiça”, mas que ele não soubera ver-lha, pois seus olhos eram os da primeira edição, os da inexperiência. Reconhece que lhe faltou não o saber quanto às reais intenções de sua interlocutora, já que ele próprio sentiu que havia algo de errado, mas sim a perícia necessária para interpretar o contrato que lhe era proposto. Essa carência foi decorrente da pequena tensão que se estabelece entre o ingênuo e os objetos de saber com os quais se relaciona. Brás Cubas percebeu que havia algo de errado no comportamento de Marcela, mas tal percepção não foi suficientemente tônica para que a interpretasse corretamente.

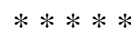


Até o momento enfocou-se a credulidade no âmbito de um fazer persuasivo explícito; isto é, em uma situação em que um sujeito tenta convencer outro do julgamento epistemológico sobre determinado fato. Contudo, evidentemente, a confiança ou a crença não estão presentes apenas na relação de um sujeito com outro, mas também na relação do sujeito com um objeto. Como demonstram Fontanille e Zilberberg ao abordar a fidúcia (1998:197-207), acredita-se não apenas em alguém, mas também em algo. Da mesma forma, a ingenuidade não se revela apenas na relação do ingênuo com o sujeito que é seu interlocutor, mas também está presente na forma como o ingênuo lida com suas crenças cotidianas, isto é, com seu objeto. Essa possibilidade está implícita na definição do dicionário de Cambridge, que considera que o ingênuo é aquele que tem "propensão a acreditar que a vida é simples ou que as pessoas são boas". Visando a examinar esse aspecto, recorremos a um romance que coloca em cena alguém considerado ingênuo, mas que não apresenta um crer excessivo em ninguém e sim uma crença na simplicidade da vida. Referimo-nos a Meursault, personagem central e narrador de $O$ estrangeiro, de Camus. Inicialmente, recorde-se que no momento em que o juiz de instrução o interroga pela primeira vez e lhe pergunta se ele havia contratado um advogado, Meursault lhe responde indagando se isso era realmente necessário, pois considerava seu caso muito simples. Ora, sendo Meursault acusado de um assassinato e não havendo dúvidas quanto à sua culpa, fica claro que sua situação era delicada, mas que ele ignora todas as implicações de seu processo e não tem qualquer experiência em relação a aspectos da vida em sociedade e, mais precisamente, a questões relativas à Justiça. Isso fica mais evidente quando seu advogado e o juiz procuram estabelecer conexões entre seu comportamento durante o velório da mãe e as causas do assassinato cometido por ele. Tais conjecturas, no entanto, não são percebidas por Meursault. Examinem-se as duas passagens:

[O Advogado] Perguntou-me se se poderia dizer que, nesse dia [o do velório], eu reprimira os meus sentimentos naturais. Respondi: - Não, porque não é verdade. Olhou-me de um modo estranho, como se eu lhe inspirasse uma certa repulsa. Disseme quase maldosamente que, de qualquer forma, o diretor e o pessoal do asilo seriam ouvidos como testemunhas, o que "seria sem dúvida muito mal para mim". Fiz-lhe notar que essa história não tinha nenhuma relação com meu caso, mas ele respondeume que se via bem que eu não conhecia a Justiça de perto.

(Camus, 1972:86) [grifos meus]

$\mathrm{O}$ advogado teme que a insensibilidade que, em sua opinião, Meursault demonstrou durante o velório da mãe seja utilizada - como de fato foi - como forte argumento da acusação. Essa possibilidade também é facilmente percebida pelo leitor, mas não por Meursault, que, apesar de enxergar a maldade na fala do advogado, não atina com tal possibilidade, tenta argumentar que a história não teria nenhuma relação com o fato e permanece confiante de que seu caso seria simples. $\mathrm{O}$ advogado então replica que se via bem que Meursault não conhecia a Justiça de perto. Mais uma vez, é a ausência de um saber - no caso, como se dão as relações em sociedade - que leva o ingênuo a manter suas conviç̧ões e a ter uma confiança que, ao final, se mostra infundada. O comportamento de Meursault é ingênuo na medida em que, ao não perceber o que está em jogo, acaba por condenar-se a si próprio com suas palavras, 
muito embora seja inocente no sentido exato de que é desprovido de malícia e, por isso, não tem a perspicácia, a competência necessária para exercer o fazer interpretativo. Aliás, é exatamente sua inocência que acaba por condená-lo.

Logo em seguida, na segunda entrevista com o juiz, quando este lhe pede que conte como ocorreu o assassinato, fica ainda mais evidente a ingenuidade de Meursault:

[...] Depois de um silêncio, o Juiz levantou-se e disse que queria me ajudar, que o meu caso interessava e, com a ajuda de Deus, faria qualquer coisa por mim. Mas antes queria dirigir-me a inda algumas perguntas. Sem transição, perguntou se eu gostava de minha mãe. Redargüi — Sim, como toda a gente — E o escrivão, que até aqui escrevia em ritmo normal a máquina, enganou-se e teve de voltar atrás. Ainda sem lógica aparente, o juiz perguntou-me então se disparara os cinco tiros a seguir.

(Camus, 1972:88) [grifos meus]

Meursault não vê lógica nas perguntas do juiz e espanta-se pelo fato de ele mudar de um assunto para outro sem fazer qualquer transição. Contudo, para o leitor, a lógica é clara e não há necessidade de outra transição, pois se tratava de demonstrar que alguém insensível a ponto de não chorar no velório da mãe seria capaz de cometer um assassinato a sangue-frio. É dessa falta de tirocínio que nasce a ingenuidade de Meursault. Observe-se, porém, que tal deficiência não faz dele um crédulo, como fica claro no capítulo final do livro, quando o padre tenta, em vão, convencê-lo da existência de Deus. Mas... mas se Meursault não se rende à argumentação bastante razoável do padre, então não há por que considerá-lo um ingênuo. Na verdade, nos dois momentos, Meursault faz a mesma operação, citada por Greimas (1983:133): seu universo cognitivo de referência o leva a avaliar e verificar a adequação do novo enunciado às formas semióticas já assumidas. A ausência de correspondência entre as assertivas de seus interlocutores e o saber por ele adquirido o impede de ver a malícia do juiz e do advogado, e de aceitar o discurso do padre; afinal, como afirma o próprio Meursault, ele desconhece o que seja um pecado. Não poderia haver maior confirmação de que o ingênuo é aquele que não possui um saber: o conhecimento do mal.

\section{REFERÊNCIAS BIBLIOGRÁFICAS}

ASSIS, Joaquim Maria Machado de. Obra completa. Rio de Janeiro: Nova Aguilar, 1997, 3 vol.

CAMUS, Albert. O estrangeiro. Tradução de Antônio Quadro. São Paulo: Abril Cultural, 1972.

FONTANILLE, Jacques. Sémiotique du discours. Presses Universitaires de Limoges, 1998.

FONTANILLE, Jacques \& ZILBERBERG, Claude. Tension et signification. Liège: Margada, 1998.

GREIMAS, Algirdas Julien. Du sens II. Paris: Seuil, 1983. Sémiotique des passions. Paris: Seuil. 1991.

\& COURTÉS, Joseph. Sémiotique, dictionnaire raisonné de la théorie du langage I. Paris: Hachette, 1979. 


\section{Como citar este artigo:}

CRUZ, Dilson Ferreira da. Algumas considerações sobre o crer e o saber. Estudos Semióticos. [online] Disponível na Internet via WWW.URL: http://www.fflch.usp.br/dl/semiotica/es. Editor Peter Dietrich. Número 4, São Paulo, 2008.

Acesso em "dia/mês/ano". 